\title{
Periorbital erythema following alcohol ingestion during treatment with topical tacrolimus
}

\author{
Kathryn Woolner BSc, Maxwell Sauder MD
}

Competing interests: None declared.

This article has been peer reviewed.

The authors have obtained patient consent.

Affiliations: Faculty of Medicine (Woolner); Division of Dermatology, Department of Medicine (Sauder), University of Ottawa, Ottawa, Ont.

\section{Correspondence to:}

Maxwell Sauder,

maxwell.sauder

@medportal.ca

CMAJ 2016. DOI:10.1503 /cmaj.150710
1 32-year-old man, who was undergoing treatment for eyelid dermatitis with topical tacrolimus ointment $0.1 \%(0.5 \mathrm{~g}$ applied twice daily for $1 \mathrm{wk}$ ), presented with periorbital erythema accompanied by a mild burning sensation that developed 30 minutes after he ingested one alcoholic beverage (Figure 1). The eruption was limited to the application site and resolved within one to two hours.

Tacrolimus ointment is a topical calcineurin inhibitor approved for the second-line treatment of atopic dermatitis in adults $(0.03 \%$ and $0.1 \%)$ and children over two years of age $(0.03 \%)$, and for maintenance therapy to prevent flares. ${ }^{1}$ Use of topical corticosteroids can result in thinning of the skin; topical tacrolimus is advantageous because it does not induce atrophy ${ }^{2}$ and is commonly used to treat eyelids and intertriginous areas. There is also evidence for the off-label use of tacrolimus for other causes of dermatitis, psoriasis, vitiligo and lichen planus. ${ }^{3}$

With tacrolimus use, the most common adverse events that occur at the application site are a burning sensation, pruritus and erythema (usually

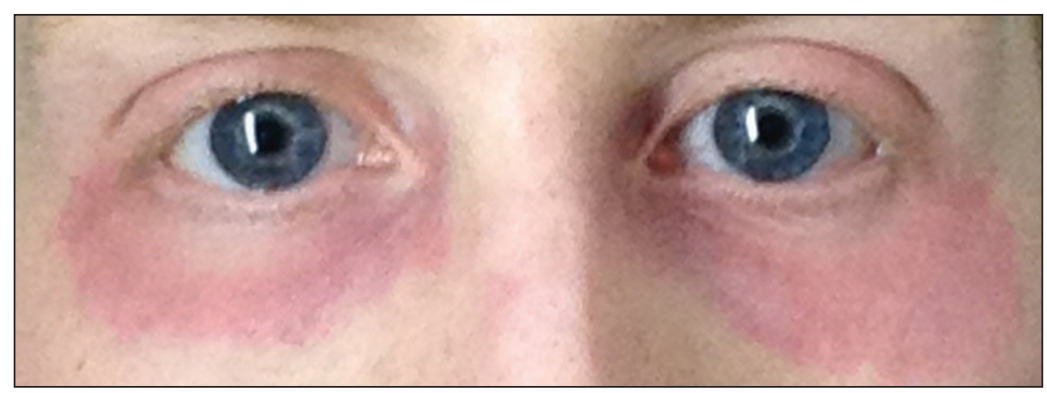

Figure 1: Well-demarcated periorbital erythema that appeared under both eyes after ingestion of one alcoholic beverage in a 32-year-old man undergoing treatment for eyelid dermatitis with tacrolimus ointment $0.1 \%$. short-lived, minutes to hours); patients typically develop tolerance within the first few days of consecutive use. ${ }^{4}$ Anecdotally, refrigerating the ointment and applying it cold may overcome the burning sensation.

In two randomized double-blind multicentre studies involving 631 adult patients with moderate to severe atopic dermatitis treated with topical tacrolimus, the arm treated with $0.1 \%$ ointment (209 patients) reported a $6.9 \%$ incidence of alcohol intolerance (skin flushing, redness and burning sensation). ${ }^{4}$ This interaction has been reported extensively but may not be widely recognized in clinical practice.

This case serves as a reminder of the importance of counselling patients about the expected brief burning sensation that resolves with consecutive use of topical tacrolimus and the interaction with alcohol ingestion. We suggest that patients be advised that these adverse events are not dangerous and will resolve within hours. Alternatively, patients may choose to abstain from alcohol ingestion during treatment.

\section{References}

1. Product monograph: Protopic $®$ tacrolimus ointment $0.03 \%$ and $0.1 \%(w / w)$ topical calcineurin inhibitor. Markham (ON): Astellas Pharma Canada, Inc.; 2010. Available: www.astellas.ca/pdf/ en/monograph/2010-09-24ProtopicProductMonograph-En.pdf (accessed 2015 June 5).

2. Kyllönen H, Remitz A, Mandelin JM, et al. Effects of 1-year intermittent treatment with topical tacrolimus monotherapy on skin collagen synthesis in patients with atopic dermatitis. $\mathrm{Br} J$ Dermatol 2004;150:1174-81.

3. Lin AN. Innovative use of topical calcineurin inhibitors. Dermatol Clin 2010;28:535-45.

4. Soter NA, Fleischer AB Jr, Webster GF, et al.; Tacrolimus Ointment Study Group. Tacrolimus ointment for the treatment of atopic dermatitis in adult patients: part II, safety. J Am Acad Dermatol 2001;44:S39-46. 